\title{
MEDIAÇÃO EXTRAINSTITUCIONAL
}

\author{
Cayo Honorato * \\ Universidade de Brasília
}

\section{RESUMO:}

Este texto percorre, de início, problemas relativos às perspectivas conceituais da mediação cultural, particularmente, no âmbito das relações entre as artes e a educação, para então apresentar e discutir, ainda que brevemente, questões ligadas a uma delimitação cognitiva das instituições, em face de uma crise desses agrupamentos sociais, entendido que a mediação, ao menos naquele contexto, é invariavelmente uma iniciativa das instituições; trazendo, por fim, um ou dois casos, que demonstram ser este o instante propício para se imaginar e realizar mediações extrainstitucionais, isto é, empenhadas em transformar o modo como nos reconhecemos por meio dessas instâncias.

\section{PALAVRAS-CHAVES:}

mediação, instituição, artes, patrimônio, sociedade.

\begin{abstract}
:
This article shows, at the beginning, problems related to some conceptual perspectives of cultural mediation, particularly in relation to the field of the arts and education, in order to present and discuss, then, albeit briefly, issues linked to a cognitive framework of the institutions, confronted with a crisis of these social groupings, understood that the mediation, at least in that context, is invariably an initiative of the institutions; bringing, finally, one or two cases which demonstrate this to be the propitious moment to imagine and realize extrainstitutional mediations, i.e., committed to transforming the way we see ourselves through these instances.
\end{abstract}

\section{KEY-WORDS:}

mediation, institution, arts, heritage, society.

\footnotetext{
* Professor adjunto no Deparamento de Artes Visuais (VIS) do Instituto de Artes (IdA) da Universidade de Brasília (UnB); doutor em Educação, na linha de Filosofia e Educação pela Universidade de São Paulo (USP); mestre em Educação, na linha de Cultura e Processos Educacionais, e bacharel em Artes Visuais pela Universidade Federal de Goiás (UFG). Email: cayohonorato@gmail.com
} 
Muitas são as mediações, mesmo dentre as chamadas mediações culturais (porque também há mediações jurídicas, comunitárias, familiares, empresariais, pedagógicas, artísticas, etc.), ainda que nos limitemos ao que é discutido por diferentes disciplinas ou áreas do conhecimento: Antropologia Social, Comunicação, Educação, Ensino da Arte, Estudos Culturais, etc. Certamente, trata-se de uma multiplicidade desconcertante, que configura um campo semântico bastante fragmentado. Por um lado, isso contribui para uma perda de especificidade do termo - que, no senso comum, parece denominar qualquer coisa "no meio" de outras -, cujo efeito seria um desgaste não negligenciável de sua capacidade crítica ou explicativa dos processos educacionais e/ou culturais nos quais toma parte. Quanto a isso, parece procedente a observação de que o termo se generaliza sem muita clareza conceitual, ou ainda, sem efetivamente transformar as práticas. Por outro lado, essa multiplicidade sinaliza a emergência, nesses mesmos processos, de muitas zonas de contato e hibridação, de encontros mas também de conflitos, entre sistemas de valores, contextos interpretativos e significados culturais diversos, que justamente configuram o lugar de atuação das mediações, ao menos de uma perspectiva crítica. Quanto a isso, a denegação da mediação como "termo muito em voga" (Ibram, 20I3: I0) parece tão somente eludir a própria complexidade dessas dinâmicas. A propósito, nesse contexto, que aceita "os desafios de uma esfera pública múltipla, alternativa, não definida previamente, poliforme e aberta" (Montero, 2012: 76),' alguma inter- ou transdisciplinaridade, até mesmo certa generalidade, teriam sem dúvida uma importância específica. Antes, porém, seria preciso demonstrar um espaço próprio de questões, talvez mais precisamente, uma "singularidade de inserção" através dessas questões.

Embora este texto não se encarregue do problema das "mediações das mediações", de uma análise comparativa das ocorrências empíricas abarcadas pelo termo, tampouco de uma teoria da mediação, que pusesse à prova sua viabilidade conceitual, a palavra mediação deve aqui ser tomada "sob rasura", como termo de nenhum modo transparente, cujas significações precisariam ser descritas na trama dos processos históricos, sociais, econômicos, culturais, etc. que as engendram; no cruzamento, portanto, de muitos discursos, saberes, instituições, práticas, apropriações etc. Em todo caso, à maneira do que o filósofo político Ernesto Laclau (20I3: 34) considera a respeito do populismo, talvez a mediação seja o "locus de um empecilho teórico". Disso resulta uma dimensão operativa do tipo de prática que podemos associar ao termo em questão: evidenciar alguns dos limites nos quais as instituições culturais abordam (ou deixam de abordar) a construção do político nas relações entre as artes, o patrimônio cultural e a sociedade. Portanto, a mediação que propomos esboçar aqui se refere às modalidades dessa construção, particularmente em face de uma crise das instituições; mais do que a uma "relação dialógica, interativa, provocativa e plena de significado para o visitante" (lbram, op. cit.: I0), geralmente referida às teorias educacionais (de Vigotsky a Paulo Freire); também mais do que a uma descrição da "circulação [das ideias e produtos culturais] em toda a esfera pública" (Desvallées \& Mairessse, 2009: 47), geralmente referida às teorias comunicacionais.

Mas por que extrainstitucional? Mesmo a mediação de conflitos, que possui um enquadramento jurídico, designa um processo extrajudicial, que não está 
sujeito a normas pré-estabelecidas, ${ }^{2}$ mas que opera, justamente, a partir da incapacidade do sistema judiciário para lidar com a esfera psicossocial, oferecendo auxílio profissional (diga-se de passagem, multidisciplinar) em uma temporalidade mais próxima à dos conflitos. Portanto, se mesmo essa mediação, que trabalha pela conciliação, reconhece a crise de pelo menos duas instituições (a família e o sistema judiciário), o que pensar a respeito da mediação cultural, que não necessariamente trabalha pela solução dos conflitos, nem pela eliminação das diferenças? Por certo, trata-se de uma crise com muitas dimensões, mas que, em geral, desde os anos 1960-70, corresponde a uma dificuldade para se deduzir, nos mais diversos setores da vida pública ou privada, um quadro comum de referências ou valores para os diferentes atores sociais; uma dificuldade que poderia nos remeter, em âmbito macropolítico, ao descrédito das representações simbólicas, de certas ligações socialmente sancionadas entre significantes e significados, bem como a uma exaustão do sistema moderno de finalidades, das metanarrativas históricas, daquilo que assegurava sem maiores protestos os rumos dos processos sociais e, então, revela-se como grandes erros da história como desenvolvimento; mas também, em âmbito micropolítico, do ponto de vista da produção de universos psicossociais, a uma duração cada vez menor dos territórios de significação da vida, dos espaços de confluência entre diferentes afetos e desejos, da vigência de suas "matérias de expressão". (Rolnik, 20I I: 34)

No que diz respeito às instituições culturais, põe-se em questão sua legitimidade enquanto representantes dos interesses gerais da sociedade, seu papel na distribuição (intelectual) para todos do que é produzido ou valorado por poucos, conforme a diretiva da democratização cultural. Particularmente no Brasil, as recentes mudanças econômicas que permitiram uma nova posição social, talvez uma nova "autoconfiança", a pelo menos 30 milhões de pessoas (Souza, 2012: 19 ss.), associadas a uma relativa popularização das novas tecnologias midiáticas, possibilitaram não só o acesso a determinados bens de consumo, mas o surgimento e a circulação de uma infinidade de práticas e produções, de uma verdadeira hiperprodução cultural distribuída, dos memes às manifestações, passando por hashtags, escrachos, saraus, ocupações, etc.; um fenômeno bastante heterogêneo, que tem sido percebido com otimismo por uns e descrédito por outros. Em todo caso, trata-se de um contexto sociocultural cada vez mais complexo e plural, no qual situações de "carência local" (esse antigo compromisso das ações educativas) começam a conviver com uma politização cultural dos setores periferizados, associada à emergência de processos criativos específicos, cada vez mais abertos e interdependentes. Diante disso, fundamentos ligados à tradição humanista ou iluminista, que ainda se manifestam na afirmação de que o museu desempenha uma "missão civilizadora e modernizadora", podem ser percebidos como um projeto hegemônico e/ou colonizador.

Do mesmo modo, para atender às "novas demandas de engajamento social", conforme a Nova Museologia, não será suficiente que o museu estabeleça "uma plataforma de comunicação modernizada entre $\circ$ visitante e o objeto exposto, de forma a promover o máximo de acesso às coleções" (Martins, 20 I I: 64-65), se o primado das coleções faz da comunicação, inadvertidamente ou não, um processo unidirecional. Tampouco, que a mediação ocupe "o vácuo entre o

2 Na verdade, encontra-se em tramitação na Câmara dos Deputados o Projeto de Lei 4.827/98, que institucionaliza e disciplina a mediação, como método de prevenção e solução consensual de conflitos. 
que a exposição pretende apresentar e a possibilidade de fruição dos diversos públicos" (Grinspum, 2000: 46), se a afirmação desse "vácuo" denota um posicionamento da fruição sempre aquém da exposição, em sentido hierárquico. Muito menos, que a mediação se empenhe em "promover a aproximação entre indivíduos ou coletividades e obras de cultura e arte" (Coelho, 1997: 247), se tal aproximação sugere aceitação e/ou conciliação.

Comprometida com a transmissão de uma cultura legítima - seja a de uma minoria privilegiada, seja a que supostamente "une os membros de uma comunidade" (Desvallées \& Mairessse, op. cit:: 47) - a um público cada vez mais amplo e indiferenciado, a mediação pode ser vista como "[...] expressão de uma metamorfose da ação pública, que busca uma nova maneira de governar a cidade e de fabricar a coesão social sem ameaçar a ordem e os modelos culturais dominantes". (Lafortune, 2008) De maneira complementar, o sociólogo Jean-Marie Lafortune propõe o conceito de médiaction cultural (em vez de médiation cultural, como se escreve em francês), cuja contribuição "[...] não tomaria unicamente a via consensual, mas implicaria o conflito". Comprometida com uma renovação da cultura por meio de uma valorização das culturas emergentes, minoritárias ou alternativas, a médiaction tem como objetivo "[...] estimular a participação [...] de modo a alterar as regras do jogo social". (Lafortune, idem)

Com isso se observa que o debate terminológico não se reduz a um mero nominalismo. Em relação à educação em museus, a mediação pode ser vista como uma concepção tanto interna (alternativamente a/ ou em confusão com: educação, interpretação, monitoria, etc.) quanto transversal (cuja trajetória de atuação passa, faz ziguezague pelo museu, de dentro para fora e vice-versa, sem fazer dele seu contexto exclusivo). Isso diverge, por exemplo, da ideia de que "a função educacional [do museu] cresceu de tal modo nas últimas décadas a ponto de o termo mediação lhe ter sido acrescido". (Desvallées \& Mairessse, op. cit.: 20) A mediação não corresponde tão somente a uma espécie de "inflação" da função educacional. A propósito, internamente à educação museal, uma mesma prática pode receber diferentes denominações (educação, mediação, etc.), como se elas fossem permutáveis entre si. Tal como afirmam Desvallées \& Mairesse, a noção de mediação (mediation), especialmente no contexto anglossaxão, é largamente recoberta pelo conceito de interpretação (interpretation). Nesse sentido, a mediação não só constrói ligações entre, de um lado, as obras, as exposições, as coleções, o patrimônio, etc., e de outro, os visitantes, os públicos, etc.; como também entre o imediato e o subjacente, entre um objeto exibido e seu conhecimento. Portanto, dessa perspectiva, a mediação pode ser definida como "uma revelação e desvelamento que leva [sic] os visitantes a compreender, e assim apreciar, e finalmente a proteger o patrimônio que ela toma como seu objeto" (Desvallées \& Mairessse, idem: 48) - o que de certo modo repõe a metáfora iluminista "[...] do museu como um sol e dos agentes ou comunidades como planetas, ou mesmo como simples satélites que rodeiam [...] e devem acessar o museu". (Montero, op. cit.: 78)

Para o educador Javier Rodrigo Montero (idem), de maneira efetivamente alternativa, uma mediação crítica trabalha "[...] em diálogo com e contra os discursos do museu, não tanto para desprestigiá-los, mas sim para descontrui-los". Além disso, compreende "[...] a educação como investigação coletiva, com base em processos de largo prazo mediante conversações culturais complexas". E por fim, "[...] reconhece as lutas sociais e os conflitos da divisão do trabalho, as- 
sim como as condições em que se produz a educação em museus". No entanto, é como se essa mediação crítica, assim como a médiaction, fizessem transbordar um excesso de significado, propriamente político, que as definições institucionais da mediação não podem comportar. A propósito, esse nos parece o fato mais relevante, inclusive, na medida em que ressignifica a própria impossibilidade de definição da mediação - o que, como dissemos, serve para eludir tanto a complexidade das dinâmicas culturais, quanto a possibilidade de transformação radical das instituições. Afinal, que disponibilidade haveria, por parte das instituições, em favorecer mediações que buscam alterar as regras do jogo no qual as próprias instituições se sustentam, ou ainda, em favorecer mediações que em parte são contrárias às instituições; que em parte buscam descontrui-las? $\mathrm{E}$, em caso negativo, por que haveria tal indisponibilidade?

Essas perguntas nos remetem a uma situação específica, que aqui propomos discutir: no âmbito das relações entre as artes e a educação (entendido que nem toda mediação é educacional), a mediação tem existido, invariavelmente, como iniciativa das instituições; o que denota por si só contornos de um funcionamento largamente impensado. Noutros termos, é o enquadramento politicoinstitucional da mediação, assim como as circunstâncias economicoculturais nas quais ela tem sido chamada a operar, que de certo modo permanecem inconscientes ou fora de pauta, nos discursos e debates sobre sua prática. Certamente, essa condição institucional da mediação está associada a uma variedade de questões: da identidade profissional do mediador (invariavelmente reduzida à prestação de serviços, e por extensão, à precariedade, provisoriedade e vulnerabilidade) às concepções de públicos (invariavelmente apriorísticas, sistêmicas e desistorizadas, limitadas a empirias totalizadas pelas categorias público espontâneo, público agendado e não-público, destituídas de qualquer imaginário politicossocial). Em todo caso, tal condição não significa, como no caso da educação museal, um simples recorte contextual, nem uma tipologia educacional específica (em relação à qual ela seria um simples truísmo), mas sim uma delimitação cognitiva, uma maneira de se fazer ser como instituição.

Sendo uma "instituição permanente" (Icom, 1999: 06), o museu tem a permanência das instituições. Segundo a antropóloga Mary Douglas (2007: 55), "No mínimo uma instituição não passa de uma convenção". Mas isso não significa que ela tenha um caráter simplesmente provisional ou instrumental. Seja qual for a instituição, ela corresponde a um agrupamento social legitimado. $O$ ponto é que, enquanto convenção social, para adquirir estabilidade, uma instituição necessita do apoio de uma convenção cognitiva paralela. Isso significa que a formação do laço social, da solidariedade, da cooperação, do acordo em relação a certas regras, etc. depende da assimilação, por parte das mentes individuais, de um modelo da ordem social, cuja legitimidade tende a justificar sua razão na natureza. A propósito, ainda segundo Douglas (idem: 57 ), "Quanto mais amplamente as instituições [enquanto organizadoras da informação] abrigam as expectativas, mais elas assumem o controle das incertezas"; mais elas buscam minimizar a entropia. No entanto, é preciso explicar a estabilidade do que estabiliza, e que se torna possível com base em uma naturalização das classificações sociais, em uma analogia entre as relações sociais e o mundo físico ou sobrenatural. Assim, 
para que não sejam desafiadas o tempo todo, as convenções sobre a divisão do trabalho, por exemplo, podem se apoiar em uma "complementaridade" entre o homem e a mulher, a cabeça e as mãos, a mão direita e a mão esquerda. Tais analogias, de certo modo, suplementam a transparência (questionável) da convenção, conferindo certo brilho (de permanência) à legitimidade.

Esse fisicalismo, segundo o filósofo Cornelius Castoriadis, é um dos tipos predominantes de resposta (juntamente com o logicismo) à questão do social-histórico - questão que nos interessa, na medida em que o museu, na sua definição, põe-se "a serviço da sociedade e de seu desenvolvimento". (Icom, op. cit.) Para Castoriadis ( 1982: 20 I ss.), o fisicalismo reduz a sociedade e a história à natureza biológica do homem, entendida como um simples mecanismo físico, mesmo quando ultrapassada, por exemplo, pelo conceito de ser genérico. ${ }^{3} \mathrm{O}$ representante mais típico dessa perspectiva é o funcionalismo (uma visão corrente da instituição, enquanto certa organização da economia, do sistema de direito, de um poder instituído, etc.), que explica a organização social como um conjunto de funções que visam satisfazer necessidades humanas preconcebidas, como se a sociedade fosse um grande organismo. Mas isso encobre um fato essencial: "as necessidades humanas, enquanto sociais e não simplesmente biológicas, são inseparáveis de seus objetos, e tanto umas quanto outros, instituídos a cada vez pela sociedade considerada". (Castoriadis, idem: 205) Em relação à história, o fisicalismo se traduz num causalismo (do mesmo modo que o logicismo se torna um finalismo racionalista), que suprime a emergência de qualquer alteridade, postulando um "encadeamento sem falhas dos meios e dos fins no plano geral", ou mais simplesmente, uma simetria entre passado e futuro.

Para esse pensamento herdado, a sociedade é um sistema (coexistência-conformação) orgânico, real ou lógico, de elementos (pessoas, coisas, ideias, conceitos, etc.) e suas relações (causalidade, finalidade, implicação lógica, etc.), suscetíveis de determinação ou definição unívoca. Nos limites dessa lógica, não há como pensar a colocação de novos elementos e relações, de elementos que não sejam elementos de um conjunto. Logo, não há como pensar a sociedade como coexistência-diversidade. Para Castoriadis (idem: 217), diferentemente, não podemos pensar o social como "unidade de uma pluralidade", mas sim como um magma, isto é, como um "modo de organização de uma diversidade não conjuntizável". O magma é o modo de ser do que se dá antes ou apesar das imposições de uma lógica identitária, prestando-se a ela (porque ele não é absolutamente caótico e, nele, termos de referência podem ser fixados), mas sem Ihe ser absolutamente congruente (porque ele não é perfeitamente organizado, ou só é organizável trivialmente, incompletamente, antinomicamente). Assim,

Temos que pensar uma multiplicidade que não é uma no sentido adquirido do termo, mas que referimos como uma, e que não é multiplicidade em sentido de que poderíamos enumerar, efetivamente ou virtualmente, o que ela "contém", mas onde podemos referir cada vez termos não absolutamente confundidos; [...] ou ainda uma reunião infinitamente confusa de tecidos conjuntivos, feitos de materiais diferentes e no entanto homogêneos, toda constelada de singularidades virtuais e evanescentes. (Castoriadis, idem: 389 )

30 conceito de ser genérico (Gattungswesen), que em Marx expressa a índole do homem como ser social, é um conceito hegeliano, que segundo Castoriadis, "representa uma etapa ulterior de elaboração lógicaontológica da physis do ser vivo aristotélico, aspecto/espécie (eidos) reproduzindo-se sempre e fixado para sempre". (Castoriadis, 1982: 205) 
Além disso, mais do que um modo de "organização", o social-histórico é também um modo de alteração. Para Castoriadis, a diferença (quantitativa) é produzida a partir de/ ou colocada "com" o que já é. Por sua vez, o novo (qualitativo) é relação de indeterminação essencial com o que já é. $O$ novo não provém do que já é, mas advém; é criação de outro eidos. Por isso, no quadro do pensamento herdado, a criação é impossível. Mesmo quando tematizada, como no caso da poiésis em Platão, ela termina encoberta para não invalidar a ideia do ser como determinidade, da inalterabilidade dos eidé como totalidade, etc.; uma posição com inúmeras consequências. Lendo o Timeu de Platão, ele observa que "a criação do mundo pelo Demiurgo não é criação, não é passagem do não-ser ao ser, ela é dirigida pelo paradigma preexistente, predeterminada pelo eidos que ela imita, repete, re-produz". Mesmo o tema moderno da "produção" (pro-ducere, hervorbringen, colocar adiante, fazer vir adiante), ligado ao tema do desenvolvimento, encontra-se em conformidade com este limite: "na melhor hipótese, as formas que o homem cria são produções, fabricadas a partir de... e segundo tal forma-norma". Eis a denegação que termina por ocultar a irrupção de uma sociedade instituinte, na qual o presente não é tão somente instrumento de determinação, mas alteridade-alteração, ruptura do que é como tal. (Castoriadis, idem: $232-236$ )

Assim, o social-histórico é também "imaginário radical, [...] estabelecimento de figuras e relação de [sic] e com essas figuras". Ele comporta "sua própria temporalidade como criação; [...] e como esta criação, ele é também esta temporalidade". Porém, esse "fluxo perpétuo de alteração" só pode ser "dando-se figuras 'estáveis' através do que ele se torna visível". E essa figura "estável" é primordialmente a instituição. Nesse sentido, a instituição é sempre instituição de uma norma. E a primeira norma instituída, o núcleo do representar/dizer social, "sem o que nada pode ser da sociedade, na sociedade, para a sociedade", é a identidade. Noutros termos, a instituição só pode ser "sendo ela própria o que ela decreta como devendo ser: identidade da norma a si mesma estabelecida pela norma para que possa haver norma de identidade a si mesmo [sic]". (Castoriadis, idem: 24I-243) Logo, para que o social-histórico não se endureça completamente na lógica identitária da instituição, ou ainda, para que a instituição não se autonomize em relação à sociedade, é preciso fazer valer a distinção entre duas temporalidades, uma explícita (identitária/imaginária) e outra implícita (autoalterante):

A sociedade e cada sociedade, [sic] é "primeiro" instituição de uma temporalidade implícita; ela é "primeiro" como auto-alteração [sic] como modo específico desta auto-alteração. Não; cada sociedade, [sic] tem sua maneira própria de viver o tempo, mas: cada sociedade é também uma maneira de fazer o tempo e de o fazer ser [sic] o que significa: uma maneira de se fazer ser como sociedade. E esse fazer ser do tempo social-histórico que é também o fazer-se ser da sociedade como temporalidade não é redutível à instituição explícita do tempo social-histórico, ao mesmo tempo em que é impossível sem esta. (Castoriadis, idem: 243 )

Portanto, ao mesmo tempo em que há uma temporalidade da sociedade (explícita ou representada), há outra que, em certo sentido, é a própria sociedade (implícita ou efetiva).Tal como exemplifica Castoriadis, a sociedade capitalista, em sua instituição temporal explícita, como tempo identitário (de demarcação), 
é "fluxo mensurável homogêneo, uniforme, totalmente aritmetizado", mas também, como tempo imaginário (da significação), "tempo 'infinito' representado como tempo de progresso, de crescimento ilimitado, de acumulação, de racionalização, de conquista da natureza, de aproximação cada vez maior de um saber exato total, de realização de uma fantasia de onipotência". Mas a temporalidade efetiva do capitalismo é, numa primeira camada, "tempo da ruptura incessante, das catástrofes recorrentes, das revoluções, de uma destruição perpétua do que já é"; enquanto noutra camada (contraditória), "tempo da cumulação, da linearização universal, [...] da supressão efetiva da alteridade, da imobilidade na 'mudança' perpétua, [...] da destruição da significação, da impotência no âmago da potência, de uma potência que se esvazia à proporção em que se estende". (Castoriadis, idem: 244)

Por fim, indissociavelmente à temporalidade do representar/dizer social, outra temporalidade deve ser instituída (no sentido identitário, mas também imaginário): o tempo do fazer social, no e pelo qual esse fazer existe e que o fazer faz existir. Este é o tempo (kairos) que contém o lapso da crise, o instante propício, a ocasião para a decisão, no qual reside a oportunidade de agir. Nesse sentido, o tempo do fazer social se encontra muito mais próximo de uma temporalidade verdadeira, pois é essencialmente irregular, acidentado, alterante; impedindo a cristalização da sociedade no instituído. Mas por que a instituição denega essa temporalidade instituinte? Castoriadis interpreta essa denegação em diversos níveis convergentes: ela corresponde às necessidades da economia psíquica dos sujeitos enquanto indivíduos sociais, inseridos no processo de socialização, além de presentificar alguma compatibilidade material entre suas experiências, que podem ser diferentes ou singulares, a fim de escaparem da psicose; ela também exprime, profundamente, a própria lógica da lógica, ou a necessidade de uma verdade atemporal e do ser como verdade; ela enfim manifesta uma necessidade da instituição como tal, que, embora nascida no tempo, pelo tempo e como ruptura do tempo, só pode ser colocando-se fora do tempo. Desse modo, conclui, esta denegação é ela mesma instituição, dimensão e modo de instituição da sociedade tal como existiu até agora e, portanto, arbitrária, no sentido de que sua revogação pela história é sempre uma possibilidade. (Castoriadis, idem: 249-252)

Assim, em última análise, não podemos jamais sair completamente da instituição, mas nossa mobilidade nela e através dela não tem limites, isto é, não tem limites naturais, lógicos ou reais, apenas limites convencionais, socialmente sancionados, o que nos permite tudo questionar, inclusive a própria instituição e nossa relação com ela. Mas o que se entende por instituição, sociedade e desenvolvimento, na definição do museu? (Icom, op. cit.) Tal como admitem Desvallées \& Mairesse (op. cit.: 19), "as definições de museu não respondem imediatamente essa questão". Em todo caso, os autores observam que o caráter institucional da coleção, em comparação às coleções privadas, é menos definido por sua aquisição e pesquisa, do que por sua introdução em um sistema classificatório. (idem: 27) No entanto, uma vez que seus critérios ou valores podem influenciar a conduta social (em alusão a sua dimensão ética), não se deveria impô-los a partir de um conjunto de regras abstratas. (idem: 32) Também eles entendem que a instituição é "uma convenção estabelecida pelo acordo mútuo entre as pessoas, sendo portanto arbitrária, ainda que historicamente datada". Ou então, em acordo com Malinowski, que as instituições são "elementos [...] construídos 
pela humanidade para responder aos problemas levantados pelas necessidades naturais da vida em sociedade". Noutros termos, que elas são "um organismo [...], estabelecido pela sociedade para satisfazer uma necessidade específica". Do mesmo modo, que o museu é uma instituição, no sentido de que é governado por um sistema legal, com base no conceito de confiança pública (public trust) ou no de propriedade pública (public ownership). (idem: 43)

Ainda segundo Desvallées \& Mairesse (idem: 43-44), o museu seria uma instituição criada para satisfazer demandas da vida em sociedade, assim como o Estado, o exército, as escolas, os hospitais, etc.; mais particularmente, uma construção humana organizada para satisfazer a necessidade social de "entrar numa relação sensorial com objetos". Os autores sugerem que enfatizar a natureza institucional dos museus significa "fortalecer seu papel normativo e a autoridade que ela tem na ciência e nas belas artes, por exemplo, ou a ideia de que os museus se mantém 'a serviço da sociedade e de seu desenvolvimento'". Curiosamente, afirmam que o campo museal pode ultrapassar o enquadramento institucional, ao refletir sobre seus próprios fundamentos, podendo até mesmo "imaginar um mundo diferente". No entanto, ao tomar como exemplo os museus virtuais, que nesse caso correspondem menos aos museus digitais que aos museus imaginários ou conceituais, parecem dizer tão somente que eles ultrapassam a noção de estabelecimento, associada a um "lugar concreto específico". Em comparação, o caráter extrainsitucional a que nos referimos não se reduz a um simples contraponto à noção de estabelecimento, mas enquadra (reflexivamente) a própria delimitação cognitiva da institucionalidade. Dessa perspectiva, não só o museu parece limitado à instituição em geral (em sentido irrestrito ao de estabelecimento), como a um tipo específico de instituição, que Castoriadis chamaria de economicofuncional.

Para o sociólogo chileno Pedro Güell (20|3), as instituições são ferramentas sociais que buscam assegurar relações de confiança e reciprocidade entre desconhecidos. Para tanto, definem um conjunto de normas, que projeta o comportamento das pessoas como solidário, para que ele possa minimamente ser antecipado.Além disso, elas trabalham junto a duas outras ferramentas: o cálculo racional e a memória social. Assim, temos por suposto que essas normas são racionais, isto é, que são guiadas por interesses gerais e não particulares. Por sua vez, nossa memória nos faz pensar que as pessoas se comportam de maneira racional, ou melhor, que elas veem vantangens na limitação de seus impulsos que possam causar danos a outras pessoas. Mas, logo se vê, o problema da confiança não desaparece com essas ferramentas. Elas podem somente atenuar nossas incertezas em relação ao comportamento do outro, que a qualquer momento, ainda que uma vez só, pode fugir ao controle das instituições. Em alguma medida, será sempre necessário supor, esperar, crer e confiar, sem fundamento racional, que o outro, salvo circunstâncias, agirá em respeito a nós, reciprocamente, colaborativamente, pacificamente. Assim, é tanto o pressuposto (indispensável) da confiança quanto a possibilidade (irredutível) da desconfiança no outro que estabelecem a função social das instituições, antes de quaisquer funções que elas venham satisfazer.

Noutros termos, as instituições se empenham em generalizar ao máximo a confiança social, permitindo que o campo/horizonte dos desconhecidos com os quais posso me relacionar seja o mais extenso possível. De fato, sem isso, a vida em sociedades complexas como a nossa seria inviável. Contudo, para que 
funcionem, as instituições precisam afirmar uma identidade geral: cidadãos, trabalhadores, consumidores, etc. (diríamos: públicos, visitantes, etc.) A reciprocidade entre desconhecidos depende, portanto, da adesão de cada um a essa identidade geral, em seus diferentes segmetos. Todavia, nem sempre essa identidade se generaliza, nem sempre ela é digna de confiança. Os motivos para desconfiar, nesse caso, não decorrem do que escapa às normas, mas das próprias normas. É quando começamos a desconfiar das próprias instituições.

Para Güell, na América Latina, colonizada pelo catolicismo iberoamericano, a confiança se organizou sobre uma base paternalista oligárquica, que dividiu o mundo social entre, de um lado, as elites dirigentes e, de outro, o povo. Nesse contexto, as elites, identificadas por vínculos familiares (depois substituídos pelo corporativismo), são depositárias da confiança; enquanto o povo e as massas, identificados à turba, à desordem, à violência, são objetos da desconfiança. No máximo, o povo é objeto de uma confiança que lhe é outorgada pelas elites; o que ele deve pagar e pelo que deve agradecer com trabalho, obediência e respeito. Nesse mundo, em que uns têm a confiança da qual os outros necessitam mas não podem produzir, as desigualdades encontram seu fundamento "racional".

Portanto, deixamos de acreditar que as instituições (nesse caso, em sentido próximo ao de corporações), baseadas em assimetrias (entre as empresas e seus funcionários, entre os bancos e seus clientes, etc.), sejam a forma de assegurar interesses comuns. Segundo Güell, há pelos menos três causas dessa crise de confiança: (I) a experiência de alguns mercados, nos quais a outorga da confiança passou às mãos dos consumidores, considerando que as empresas precisam deles para sobreviver; (2) o descrédito da ideia de que as corporações (as indústrias farmacêuticas, as empresas de transporte coletivo, etc.) representam interesses comuns, a partir da revelação de que seus interesses são particulares; (3) a expansão dos direitos individuais, que confere dignidade às pessoas por sua existência social, e não por suas relações com as instituições - o que pressupõe a conquista de uma confiança que não depende da "generosidade" de nenhum sujeito em particular, na medida em que se apoia num poder da sociedade.

Para Güell, nem todas as consequências dessa crise são negativas: "[...] temos agora a oportunidade de superar essa forma insustentável de confiança social e avançar formas cidadãs, com base em direitos, simetria de dignidades, critérios efetivamente universais e uma penalização efetiva para os que decepcionam a confiança pública". Contudo, mais do que buscar a restauração de uma universalidade originária (tal como a posição do autor parece sugerir), pareceria-nos mais decisivo pensar/realizar instituições capazes de abrigar, nelas mesmas, a impossibilidade de interesses ou identidades gerais, à maneira da multiplicidade magmática de Castoriadis; ainda que para isso uma confiança sem fundamento no outro, que não seria um outro eu, fosse imprescindível.

Por certo, não se poderia comparar os museus a empresas, uma vez que, por definição, são instituições "sem fins lucrativos" (Icom, op. cit.); mesmo no caso dos museus privados. No entanto, o perfil educacional dos museus, atualmente, é uma das principais justificativas para os aportes financeiros que recebem de fontes públicas ou privadas (Martins, op. cit.: 17) - o que não necessariamente resulta num reconhecimento da educação praticada nos museus. No caso do financiamento privado, no Brasil, majoritariamente por meio de renúncia fiscal, tal apoio obedece às leis de formação do capital simbólico, que medem os efeitos dos projetos educativos em função do quanto podem valori- 
zar a imagem dos patrocinadores. No caso do financiamento público, trata-se de um apoio difuso, interessado sobretudo na construção de consensos a respeito da utilidade social dos museus. Segundo a educadora Luciana Conrado Martins (idem: 257), "Ao mesmo tempo em que [...] a educação parece ser uma das propulsoras das diretrizes presentes na Política Nacional de Museus [...] ela não aparece com funções especificamente definidas no Estatuto de Museus, nem é privilegiada de forma específica nos editais de fomento do lbram".. A premissa, no caso, é que, hoje, sendo esta sua função social mais proeminente, a educação estaria imiscuída/diluída em todas as ações do museu.Assim, as instituições precisam tanto sutentar um discurso educacional consistente (isto é, autorreferente), sem o qual "têm pouca ou nenhuma chance de captar recursos" (idem: 69 , nota), quanto adequar/aderir esse mesmo discurso à lógica do patrocínio, em conformidade ao gosto de muitas "vozes externas". (idem: 267-273)

E se, conforme Castoriadis (op. cit.: 243), a instituição só pode ser "sendo ela própria o que ela decreta como devendo ser:identidade da norma a si mesma estabelecida pela norma para que possa haver norma de identidade a si mesmo [sic]", tanto melhor se o discurso "consistente" não demonstra sua suscetibilidade às vozes externas - o que ocorre segundo uma discriminação específica. Isto é, não só as vozes dos patrocinadores, que, como vimos, têm uma influência decisiva, não podem aparecer com tal; como as vozes dos públicos, que, por sua vez, estão aparentemente representadas em primeiro plano, têm geralmente pouca ou nenhuma influência efetiva. Do mesmo modo, é mais evidente o empenho das instituições em generalizar a confiança social que lhes é depositada, do que em praticar formas de participação que resultem num "acordo mútuo entre as pessoas", relativamente ao quê e como deve ser preservado, exibido, etc. Mesmo assim, é preciso ressalvar que, nesse caso, o uso social das instituições seria por elas outorgado aos públicos, portanto, não necessariamente uma conquista social das instituições pelos públicos.

Nesse sentido, é importante notar a consonância entre o que Martins (op. cit.: 356) chama de "campo recontextualizador oficial" (o discurso das políticas públicas, entre outros agentes) e o "campo recontextualizador pedagógico" (a ideologia expressa pelos educadores), "associada, principalmente, à perspectiva inclusiva e de diálogo como todos os tipos de públicos". Não por acaso, a educação nesse contexto (institucional), seja positivista ou construtivista (Martins, idem: 124), tem se limitado a um tipo de endereçamento, de caráter invariavelmente provedor, mais interessado em ser causa de alguma modificação nos públicos, do que em se posicionar diante das consequências de uma participação efetiva dos públicos. São identidades gerais o que ela projeta, em sobreposição aos públicos enquanto formações emergentes. Mesmo os públicos específicos, com suas características e necessidades próprias, isto é, identitárias, costumam ser tratados pela mediação institucional segundo algum grau de homogeneidade, sendo "a tipologização dos públicos [...] uma forma de controlar o processo educacional". (idem: 360 ) 
Os interesses gerais que as instituições representam (ou dizem representar), a fim de se apresentarem como pólos da confiança social, podem ser questionados em diferentes escalas. Analisando os pressupostos do programa da Unesco dedicado ao patrimônio mundial, o antropólogo argentino Néstor Canclini (2012:65-98) entende que as atividades destinadas a defini-lo, preservá-lo e difundi-lo quase sempre incorrem numa simulação: "fingem que a sociedade não está dividida em classes, gêneros, etnias e regiões, ou sugerem que essas fraturas não têm importância diante da grandiosidade e respeito ostentados pelas obras patrimonializadas". A atribuição de um "valor universal excepcional" - segundo "parâmetros mutantes", estéticos ou pluralistas - a um conjunto tão variado de bens, lugares, saberes, etc. parece disponibilizar a todos o que efetivamente não pertence a todos, reproduzindo os privilégios daqueles que, em cada época e contexto, dispuseram dos meios econômicos e intelectuais para imprimir a esses bens um valor "mais elevado". Como observado pelo autor, o mapa do patrimônio mundial ainda é bastante eurocêntrico. Mesmo nos demais continentes, a lista revela um eurocentrismo indireto, mostrando preferência por ex-colônias europeias, ou ainda, por modelos urbanos europeus reproduzidos alhures.

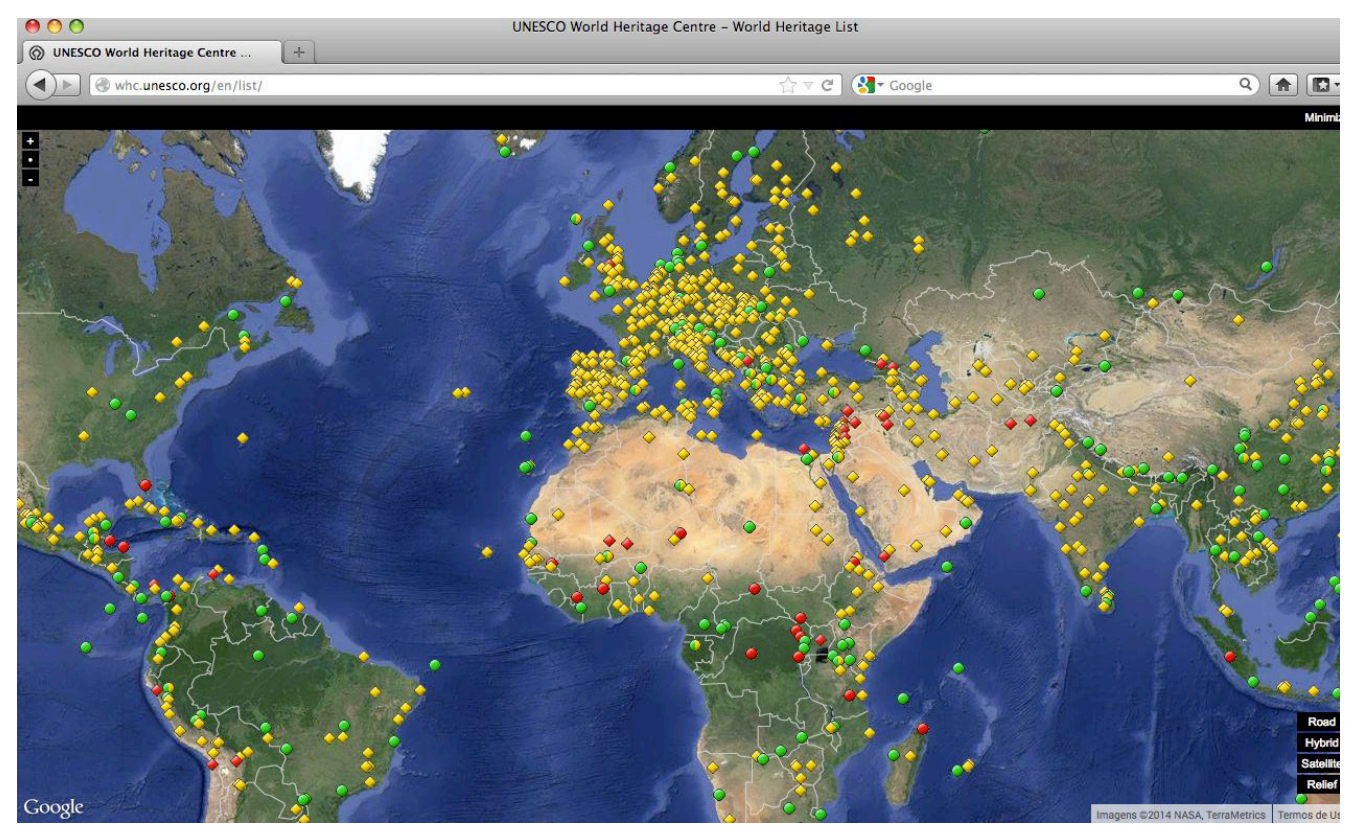

Vista do Mapa Interativo, disponível no site da Unesco, com a lista do Patrimônio Mundial em 20I4. (Captura de tela)

Assim, como pensar que devam ser valorizados por todas as culturas? A distribuição geocultural do valor parece desconsiderar tanto sua constituição multifatorial, isto é, que a excepcionalidade do patrimônio também é fabricada pela publicidade (turística, midiática ou religiosa); quanto a dificuldade das classes populares e das sociedades periferizadas para transformar seus bens em patrimônios mundializados, para institucionalizá-los como "bens superiores", que merecem ser conservados e estudados. Nessa distribuição divisora, promovida por uma globalização seletiva, "Uns [países africanos, asiáticos e latinoamericanos] aportam saberes e imagens locais; outros [centros europeus], os dispositivos de financiamento, organização, interpretação e capacidade de universalizar os 'produtos'". (Canclini, idem: 86) Embora os propósitos da Unes- 
co sejam declaradamente altruístas, sua ambição não faz senão amplificar essas contradições e desigualdades, mitigando o que deveria ser percebido como um espaço de disputa material e simbólica.

Para Canclini, não é possível escolher um conjunto "autêntico" de bens, "[...] separando-os dos usos sociais que historicamente os foram modificando, como o desenvolvimento urbano, as indústrias comunicacionais, a inserção em redes de comercialização e representação midiáticas". (idem: 74) O antropólogo salienta não desconhecer "a importância e a necessidade de preservar os bens que testemunham desenvolvimentos ou momentos extraordinários das culturas". (idem:97) No entanto, sua preferência por examinar os usos do patrimônio propõe uma reformulação do estudo e da gestão desses bens, "[...] não só como conservação e consagração de peças com valores extraordinários, mas também como participação nos dilemas cognitivos, éticos e sociopolíticos da interculturalidade". (idem: 96) Mais do que insistir na afirmação de um conceito abstrato de humanidade, é preciso "assumir a inconstância conceitual, os significados variáveis nos usos dos bens e situar-se eficazmente nas disputas internacionais". (idem: 97)

Curiosamente, é em nome de critérios efetivamente universais, democráticos e populares, que parte dos mediadores da $9^{\mathrm{a}}$ Bienal do Mercosul decidiu, no último dia da mostra (em I 0/I I/I3), fazer uma "paralis(AÇÃO)", em protesto contra o que percebeu como "[...] arbitrariedades no tocante ao uso [...] [dos] espaços [expositivos], expressas por práticas institucionais que restringem o acesso do público visitante segundo critérios discriminatórios e segregatórios". Em declaração de 05/ I I/I3, o Coletivo Autônomo de Mediadorxs (20 I 3b) relata que a realização de um jantar de arrecadação, em 04/I0/I3, nas dependências do MARGS (Museu de Arte do Rio Grande do Sul), que então sediava parte da exposição, além de dificultar o acesso do público em horário de visitação, em função dos preparativos do evento, interferiu no trabalho dos mediadores, que não foram avisados da cerimônia, contrariando normas de segurança e preservação das obras - estabelecidas pelas próprias instituições e que deviam ser observadas tanto pelos visitantes quanto pelos mediadores -, uma vez que o jantar foi realizado no próprio espaço expositivo, ao lado de obras em exibição.

Outros episódios relatados, como no caso de uma performance com vagas limitadas, realizada em 24/I0/13, no Santander Cultural (outra instituição que também sediava parte da mostra), denotam o favorecimento de pessoas relacionadas "[...] a uma determinada condição social de distinção, status e privilégio, bem como a vínculos pessoais com figuras da Fundação Bienal", em detrimento das pessoas que aguardavam na fila, já que o programa havia sido amplamente divulgado. Nos termos em que vêm a público, são práticas que contrariam tanto o princípio da "universalidade do acesso", conforme o Estatuto de Museus (Lei I I.904 de 2009), quanto alguns artigos das Leis de Incentivo à Cultura em âmbito estadual (Lei I 3.490 de 20 I0) e federal (Lei 8.3 I 3 de I99I), que condicionam o incentivo à promoção do acesso amplo e irrestrito. Na mesma declaração, - Coletivo afirma dissociar-se completamente dessas práticas, reivindicando o respeito a "[...] todo e qualquer tipo de público [...] independente de gênero, classe, etnia ou idade". 


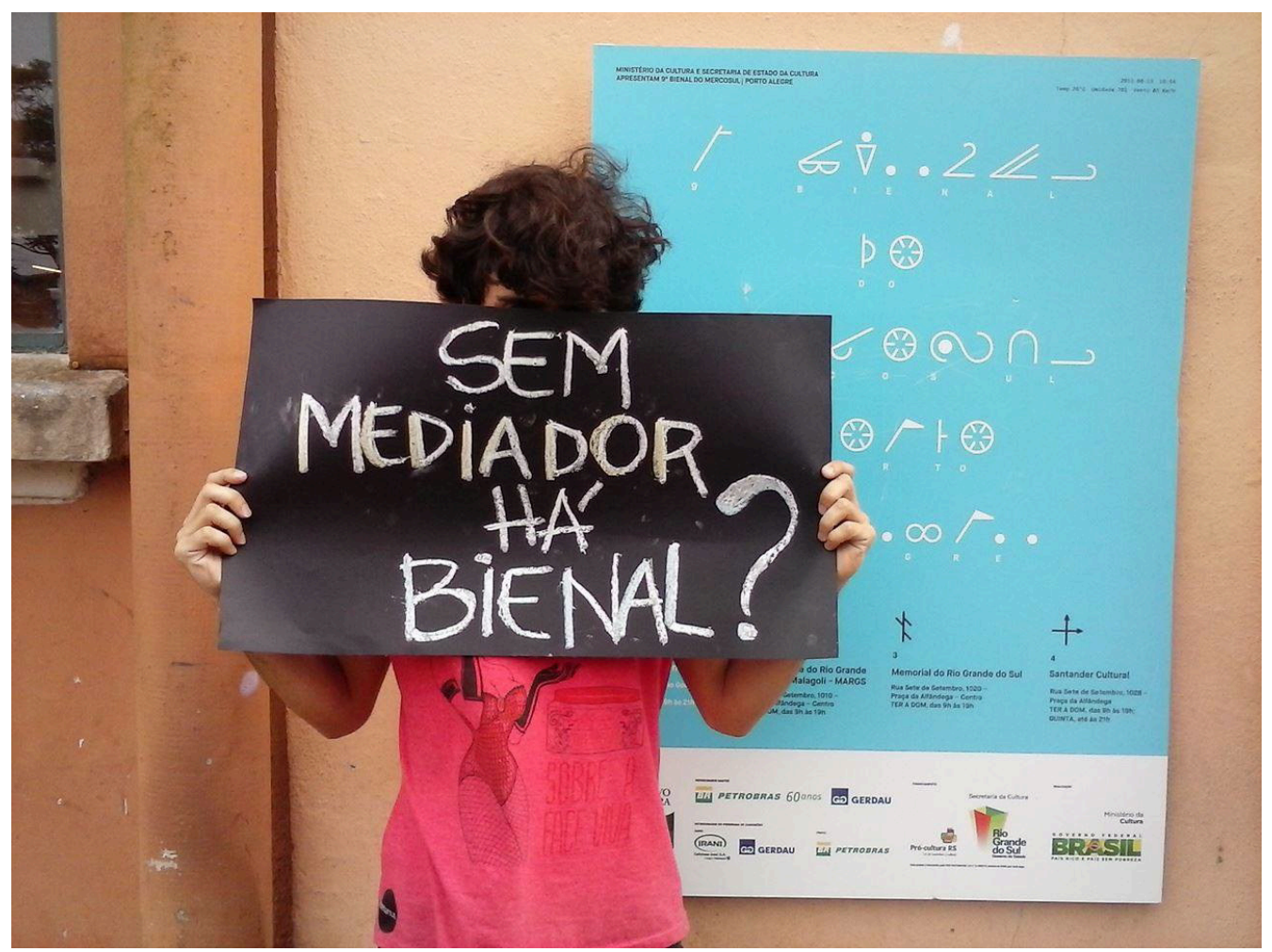

Registro da "paralis(AÇÃO)" dos mediadores da Bienal do Mercosul em I0/I I//3, por Leonardo Barreiro. (Divulgação)

Em resposta ao ocorrido, a Fundação Bienal do Mercosul afirmou em nota que "[...] respeita o direito de expressão dos cidadão [sic] e está à disposição para dialogar em um próximo momento". (Zero Hora, 20I3) É significativo do comportamento institucional que a Fundação declare "disposição para dialogar", quando na verdade o diálogo já havia sido convocado, na clara exposição pelos mediadores das questões diante das quais ela devia se posicionar. Também há relatos de desvio de função, assédio moral, perseguições, abuso de poder, agressões, etc., cometidos por diferentes instâncias das diferentes instituições, em relação aos mediadores e visitantes. Não surpreende que esse contexto, onde se entrecruzam muitos interesses, por vezes divergentes, seja tenso de conflitos. Mas chama a atenção que a instituição atue de modo a apaziguá-los. Na mesma nota, é nítida a preocupação da Fundação em comunicar que "[...] ○ funcionamento dos espaços expositivos [...] segue normalmente", que "A paralisação da mediação ocorrida no dia de hoje foi parcial", que "[...] temos mediadores para atender o público em todos os espaços".

Como se vê, além de atuar pela normalização, a Fundação apela a um sentido de público impassível às reivindicações dos mediadores, como se elas fossem meramente privadas, devendo ser minimizadas. Certamente, são sentidos de público em disputa. É importante notar que os mediadores não cruzaram os braços simplesmente. Conforme o relato de um deles, no dia da "paralis(AÇÃO)", "Enquanto algun(a)s [sic] colegas se dedicavam à confecção dos cartazes, outro(a) s realizavam a distribuição dos panfletos e da declaração [...]. Ora iniciávamos o diálogo com alguém que passava, ora éramos interpelado(a)s por quem circulava". (CAM, 20I3c) Também é preciso considerar que, desde o episódio do jantar, os mediadores iniciaram um processo de auto-organização, em torno da elaboração da declaração, da constituição do Coletivo, da própria produção 
da "paralis(AÇÃO)", etc., ao qual se dedicaram, em inúmeras assembleias presenciais e debates à distância, para além do expediente de trabalho, para além inclusive do tempo da exposição.

Em carta de 27/I2/I3, endereçada à Fundação Bienal, o Coletivo (20|3a) se define como uma "associação livre e não-institucional". Suas reivindicações contemplam não só as condições de trabalho dos mediadores, como também as da equipe de segurança; pedem o fim das chamadas "visitas VIP" e acessibilidade total para os públicos com necessidades especiais; defendem o controle social das instituições privadas que se valem de financiamentos públicos para existir ou realizar seus eventos, etc. Contudo, na medida em que se depara com as questões de formação do laço social, que condicionam a própria sustentação de suas reivindicações, o Coletivo se confronta com problemas semelhantes ao da instituição, ou melhor, de se fazer instituição. Nesse sentido, ele alterna entre reivindicações trabalhistas, na direção do que seria um "sindicato de mediadores", ou talvez, um mecanismo de denúncia das arbitrariedades institucionais, e reivindicações mais amplas, ligadas à privatização dos espaços públicos em Porto Alegre, por exemplo, na direção do que viria a se configurar enquanto um movimento social. Aqui temos um limite a ser transposto pelo imaginário instituinte. Afinal, como organizar essa mediação que atravessa a instituição? Em todo caso, o Coletivo faz aparecer, concretamente, que é preciso haver mediação para além da instituição.

No sentido que gostaria de sublinhar, e que só pode ser extrainstitucional, - papel público que a mediação tem a desempenhar diz menos respeito à "[...] transformação cognitiva de seus visitantes [dos museus] em relação ao patrimônio por eles preservado", do que a uma transformação radical das próprias instituições, e do modo como nos reconhecemos e nos permitimos reinventar (ou não) por meio delas, considerando que, em sua delimitação cognitiva, para a preservação de sua própria identidade como norma, elas tendem a se autonomizar em relação ao social-histórico, desperdiçando uma infinidade de oportunidades de aprendizagem - um desperdício produzido no mais das vezes por um discurso voluntarista, articulado em nome do diálogo, do encontro e da experiência. De resto, uma mediação extrainstitucional tem menos interesse em corresponder às "características e necessidades" (identitárias) dos visitantes, de maneira semelhante à relação das empresas com seus clientes, do que em potencializar contrapúblicos, que se manifestam, sem identidade, numa divisão de cada um consigo mesmo, numa quebra de ligação com as expectativas de sua inserção em determinados ritos e/ou processos de socialização.

\section{Referências}

CANCLINI, Néstor G. A sociedade sem relato: antropologia e estética da iminência; tradução de Maria Paula Gurgel Ribeiro. São Paulo: Edusp, 2012.

CASTORIADIS, Cornelius. A instituição imaginária da sociedade [1975]; tradução de Guy Reynaud. 5. ed. Rio de Janeiro: Paz e Terra, 1982.

COELHO, Teixeira. Dicionário crítico de política cultural. São Paulo: lluminuras, 1997. COLETIVO AUTÔNOMO DE MEDIADORXS. À Fundação Bienal de Artes Visuais do Mercosul, Carta de Reivindicações do Coletivo Autônomo de Mediadorxs. [20I3a] Disponível em:<http://migre.me/iSxta>, acesso em 21/04/l4.

.Declaração. [20।3b] Disponível em:<http://migre.me/iStnl>, acesso em 21/04//4. 
Quando falhas operacionais são desigualdades estruturais - por que o Coletivo Autônomo de Mediadores realizou uma paralisação na $9^{\mathrm{a}}$ Bienal do Mercosul/Porto Alegre. [2013c] Disponível em: <http://migre.me/kLMDI>, acesso em $31 / 07 / 14$.

DESVALLÉES,André \& MAIRESSE, François (eds.). Key concepts in Museology. s.l.: Armand Colin; ICOM, 2009.

DOUGLAS, Mary. Como as instituições pensam; tradução de Carlos Eugênio Marcondes de Moura. São Paulo: Edusp, 2007.

GRINSPUM, Denise. Educação para o patrimônio: museu de arte e escola - responsabilidade compartilhada na formação de públicos; orientação de Maria $\mathrm{He}-$ lena Pires Martins. São Paulo: FE/USP, 2000. I57 pp. [Tese de doutorado]

GÜELL, Pedro. Crisis de confianza en las instituciones: ¿qué es eso? s.l.: s.n., s.d., 07 pp. (PDF) [2013] Disponível em: <http://migre.me/ktnBL>, acesso em I5/07//4.

IBRAM. Documento Preliminar do Programa Nacional de Educação Museal. Brasília: s. n., 2013.84 pp. (PDF) Disponível em: <http://migre.me/ks2cw>, acesso em |4/07/| 4 .

ICOM. Estatutos. In: Cadernos de Sociomuseologia, v. I 5, n. I 5 ( I 999); tradução de Ana Tavares. Disponível em: <http://migre.me/kHzCo>, acesso em 29/07//4. [Versão adotada pela 16a Assembleia geral do ICOM (Haia, Países-Baixos, 5 de Setembro de 1989) e modificada pela I $8^{\mathrm{a}}$ Assembleia geral do ICOM (Stavanger, Noruega, 7 de Julho de 1995)]

LACLAU, Ernesto. A razão populista; tradução de Carlos Eugênio Marcondes de Moura. São Paulo:Três Estrelas, 2013.

LAFORTUNE, Jean-Marie. De la médiation à la médiaction: le double jeu du pouvoir culturel en animation. Lien social et politiques, n. 60. s.l.: Érudit, 2008, pp. 49-60. Disponível em: <http://migre.me/ftWbY>, acesso em 06/I2//3.

MARTINS, Luciana C. A constituição da educação em museus: o funcionamento do dispositivo pedagógico por meio de um estudo comparativo entre museus de artes plásticas, ciências humanas e ciência e tecnologia; orientação de Martha Marandino. São Paulo: FE/USP, 20 I I. 390 pp. [Tese de doutorado]

MONTERO, Javier R. Experiencias de mediación crítica y trabajo en red en museos: de las políticas de acceso a las políticas en red. Revistas Museos, n. $3 \mathrm{I}$. Santiago: DIBAM, 2012, pp. 76-87.

ROLNIK, Suely. Cartografias sentimentais: transformações contemporâneas do desejo. Porto Alegre: Sulina; Ed. da UFRGS, 20 I I.

SOUZA, Jessé. Os batalhadores brasileiros: nova classe média ou nova classe trabalhadora? 2. ed. rev. e ampl. Belo Horizonte: Ed. da UFMG, 2012.

ZERO HORA. Mediadores fazem manifestação contra organização da Bienal. [20।3] Disponível em: <http://migre.me/iSw7R>, acesso em 2 I/04/l4. 